DOI: $10.1515 / j b c r-2015-0116$ Case Report

\title{
INTERNAL INCARCERATION OF LEFT PARADUODENAL HERNIA WITH NECROSIS OF PROXIMAL JEJUNUM AND ATYPICAL RECONSTRUCTION OF THE PASSAGE: A CASE REPORT
}

\section{Pentcho T. Tonchev, Sergei D. Iliev, Ivailo M. Presolski}

Department of Propedeutics of Surgical Diseases, Medical University - Pleven, Bulgaria

\section{Corresponding Author: \\ Pencho Tonchev \\ Medical University - Pleven \\ 1, Kliment Ohridski str. \\ Pleven, 5800 \\ Bulgaria \\ e-mail:ptonchev@gmail.com}

Received: December 01, 2013

Revision received: December 09, 2013

Accepted: December 27, 2013

\section{Summary}

Internal hernias are rare and most of them are diagnosed intraoperatively. We present a case of a 53-year-old man with proximal intestinal obstruction, caused by incarcerated internal hernia. During the operation, a proximal portion of $40 \mathrm{~cm}$ of the jejunum was found herniated and strangulated in the lesser sac through an opening of the transverse mesocolon. The jejunum was necrotic and local purulent peritonitis was present. After resection of the proximal $40 \mathrm{~cm}$ of the jejunum, the passage was restored using an unconventional approach. The distal duodenum was closed and, to protect the stump, the duodenum was ligated between its second and third parts. A latero-lateral anastomosis was made between the first part of duodenum and the jejunum. Anatomical, clinical and radiological findings, diagnosis and treatment of paraduodenal hernias are discussed in brief.

Key words: internal hernia, paraduodenal hernia, duodenal occlusion, duodenojejunostomy, duodenal diverticulzation

\section{Introduction}

Internal hernias in the abdominal cavity are difficult to diagnose and are often detected during operation. Paraduodenal hernias are the most common. Frequency of paraduodenal hernias reported is 0.2$0.9 \%$, with left paraduodenal hernia accounting for $75 \%$ and right - for $25 \%$ of them [1]. More than 10 recesses and fossae near the ligament of Treitz have been described. Most important are the paraduodenal fossa of Landzert (left), superior fossa of Treitz and inferior fossa of Treitz (Figure 1) [2,3]. Left paraduodenal hernias are typically directed left and downwards behind the descendent mesocolon. Left and right paraduodenal hernias are result of partial malrotation of midgut during first weeks of gestation [4]. 


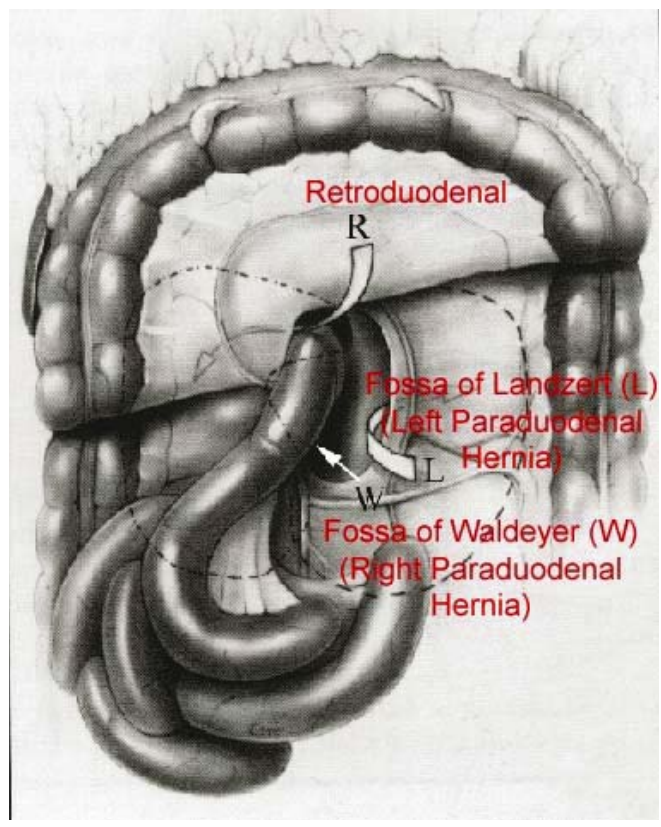

Figure 1. Anatomy of paraduodenal hernias (image taken from http://www.med-

ed.virginia.edu/courses/rad/gi/hernias/paraduodenal. html [3]

\section{Clinical picture and diagnosis}

Symptoms range from asymptomatic through discomfort to severe colicky pain and palpable mass in the left epigastric region. Bowel obstruction, strangulation, necrosis and peritonitis are the major complications. Diagnosis is difficult. Often, the only X-Ray symptom may be a single air-fluid level to the left of or behind the stomach. CT is the study of choice in such cases [5]. Surgery includes reduction of herniated bowel, closure of the orifice and resections and anastomoses in case of necrotic gut. Laparoscopic surgery is often the first choice treatment [6].

\section{Case report}

After a diet mistake at New Year's Eve, a 53-year old male presented with vomiting, upper abdominal pain, leukocytosis $\left(24 \times 10^{9}\right)$ and increased serum alpha amylase in serum (339 UI) and urine (2140UI). The patient was diagnosed with of acute pancreatitis. Clinical examination revealed pain on deep palpation of the upper abdomen, which appeared distended and swollen. Ultrasound revealed enlarged hypoechogenic pancreas. Abdominal X-ray examination showed no signs of intestinal obstruction or free intrabdominal gas. Routine treatment for acute pancreatitis was started with fluids i.v, placement of a nasogastic tube and spasmolytics. After two days the subsided but discharge from a NG tube was high $(>700 \mathrm{ml} / 24 \mathrm{~h})$. The abdominal X-ray on day 4 showed a single air-fluid level in the left epigastric area (Figure 2).

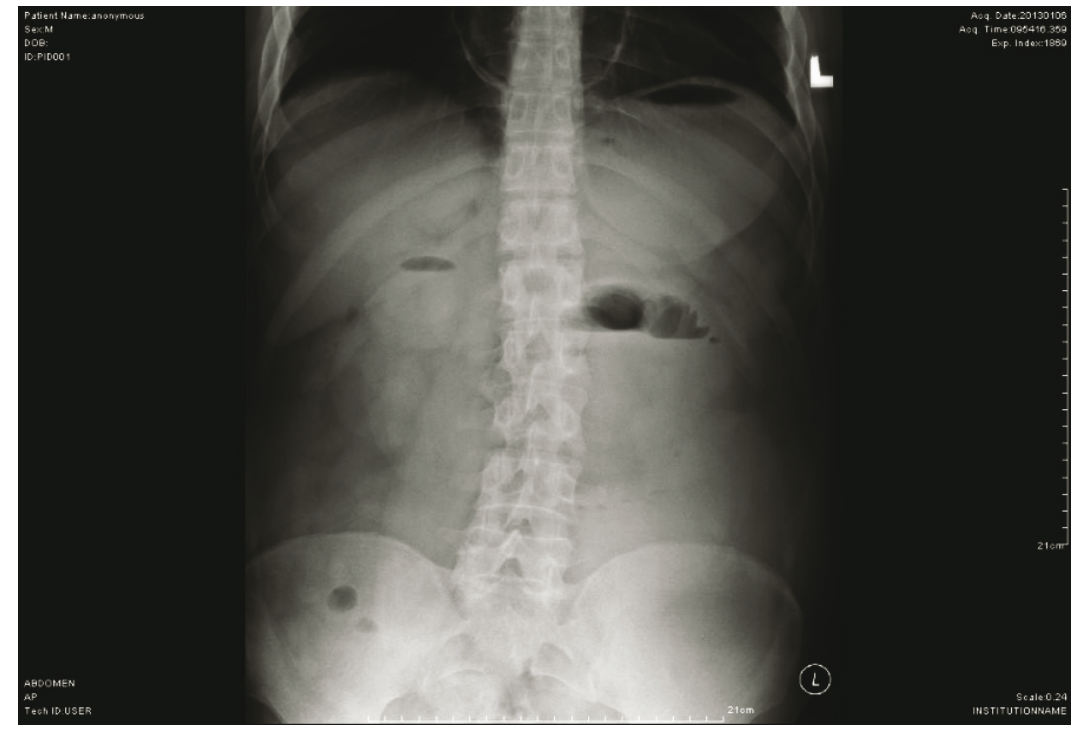

Figure 2. Abdominal X-ray showing single hydroaeric level in left epigastric area (day 4) 
CAT was performed on day 5 and revealed a normal pancreas and peripancreatic spaces. A bloated intestinal loop was found left to the duodenum, displacing the posterior stomach wall (Figure 3). The patient was operated on on the same day. Intraoperatively, purulent peritonitis was found in the omental bursa, with herniation, strangulation, necrosis and perforation of the proximal jejunum through an opening in the transverse mesocolon left from the ligament of Treitz and middle colic artery. The jejunal loop was gently reduced and the necrotic bowel including distal $2 \mathrm{~cm}$ of duodenum was resected. Construction of a duodenojejunal anastomosis at this place was very risky, the patient being with localized peritonitis and malnutrition after 5 days nil per os. The distal duodenum was closed with interrupted sutures on two layers. To protect the stump, the duodenum was mobilized by Kocher and occluded between its second and third parts, below the papilla, at the lower edge of pancreas, using single thread covered with a second layer of interrupted seroserous sutures. A latero-lateral anastomosis was made between the first part of duodenum and the jejunum. A triluminal tube was placed distal to anastomosis to provide enteral nutrition. Drains were placed in the omental bursa and in contact with the anastomosis. The postoperative period was uneventful except for a subcutaneous wound dehiscence on the 10th day. Discharge of purulent discharge from the drain in omental bursa gradually decreased and stopped on day 14 . The patient was discharged on the $18^{\text {th }}$ postoperative day.

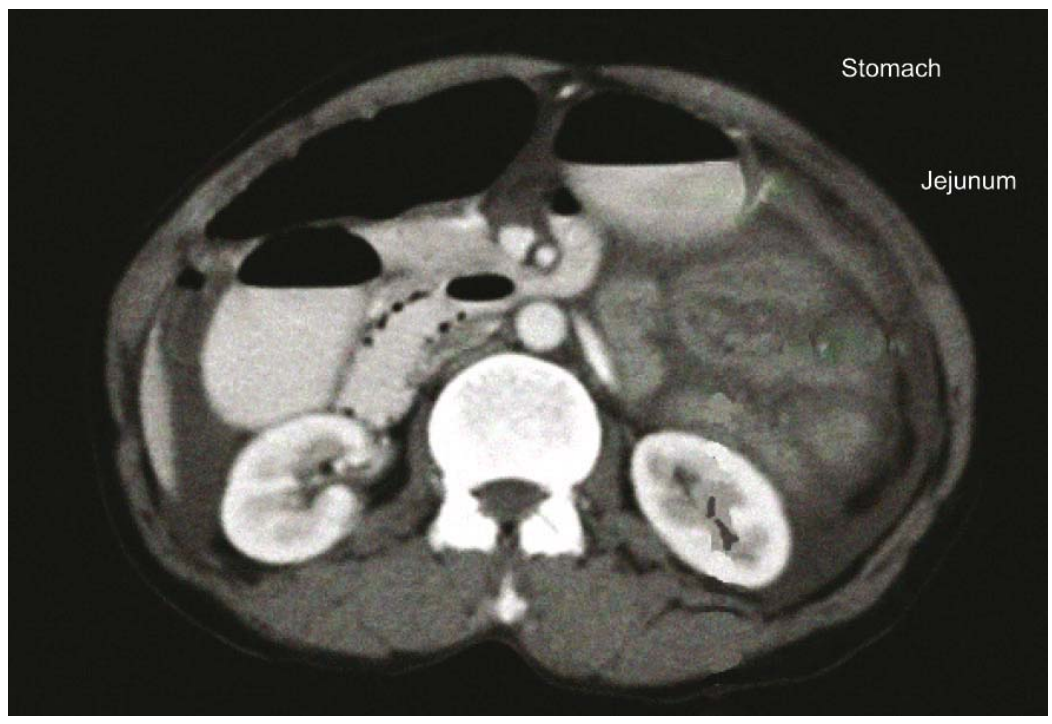

Figure 3. Dilated intestinal loops left to the duodenum, displacing posterior stomach wall

\section{Discussion}

Our case differs from a typical left paraduodenal hernia. A strangulated jejunum was found in a lesser sac rather than in the typical bag-like space behind descendent mesocolon. In the classical left paraduodenal hernia, the direction of the bag is left and down, while in this case it was left and up. Our case is similar to that described by Shoji [6] and that of Stewart [7].

The diagnosis was delayed. The operation was performed after a period of malnutrition and revealed localized peritonitis. Diagnosing mild pancreatitis usually excludes early surgical activity, so the operation was postponed.
Reconstruction of the passage is very risky in such patients. In the literature, reported mortality of trapped internal hernia with necrosis and peritonitis is $50 \%$ [5].

Considering localized purulent peritonitis and malnutrition, decision about the type of reconstruction was not easy. Pyloric or proximal duodenal occlusion is a method of choice in patients with retroperitoneal rupture of duodenum [8]. Changing the place of anastomosis to anterior duodenal wall bellow the pylorus was on account of the peritonitis in the lesser sac which could compromise the anatomical anastomosis. Occlusion of the duodenum between the second and third part was 
to protect the closure of the distal duodenum. Similar technique was reported for patients with duodenal perforation, retroperitoneal tumor and sepsis [9].This approach proved to be appropriate. Indeed, there was no leakage of bile

\section{References}

1. Blachar A, Federle MP, Dodson SF. Internal hernia: clinical and imaging findings in 17 patients with emphasis on CT criteria. Radiology. 2001;218(1):68-74.

2. Skandalakis JE, Colborn GL, Weidman TA, Kingsnorth AN, Skandalakis LJ, Skandalakis PN. Peritoneum, Omenta, and Internal hernias . In: Skandalakis JE, editor. Surgical Anatomy: The embryologic and anatomic basis of modern surgery . Athens, London: Paschalidis Medical Publication, McGraw-Hill; 2004. p. 493-549.

3. Spencer B. Gay, Hubert A. Shaffer Jr, et all. Intro to GI Radiology [Internet]. Introduction to radiology. [cited 2014 Mar 4]. Available from: http://www.meded.virginia.edu/courses/rad/gi/hernias/paraduode nal.html

4. Bartlett MK, Wang C, Williams WH. The surgical management of paraduodenal hernia. Ann Surg. $1968 ; 168(2): 249-54$. or pancreatic juice, nor was there an anastomotic leak.

This type of atypical reconstruction was made in a patient with complications and an atypical diagnosis and actually saves patient's life.

5. Martin LC, Merkle EM, Thompson WM. Review of internal hernias: radiographic and clinical findings. AJR Am J Roentgenol. 2006;186(3):70317.

6. Shoji T, Nishiyama R, Oba K, Azuma M. Left Paraduodenal Hernia Successfully Treated with Laparoscopic Surgery: A Case Report. Case Rep Gastroenterol. 2007;1(1):71-6.

7. Stewart JOR. Lesser sac hernia. Br J Surg. 1962;50(221):321-6.

8. Nathens A. Blunt Abdominal Trauma. In: Schein M, Rogers PN, Assalia A, editors. Schein's common sense emergency abdominal surgery: an unconventional book for trainees and thinking surgeons. 3rd ed. Heidelberg: Springer; 2010. p. 314.

9. Kostroff KM, Turnbull AD, Rotstein LE, Raaf JH. Duodenojejunostomy and stapled occlusion for distal duodenal perforation from malignant retroperitoneal tumors. J Surg Oncol. 1984 Aug;26(4):252-5. 